\title{
A numerical scale to assess the outcomes of metabolic/bariatric surgery (NOMS)
}

\author{
Maciej Michalik ${ }^{1}$, Maciej Bobowicz², Henry Buchwald ${ }^{3}$ \\ ${ }^{1}$ Department of General and Minimally Invasive Surgery, University of Warmia and Mazury, Olsztyn, Poland \\ ${ }^{2}$ Department of Oncological Surgery, Medical University of Gdansk, Gdansk, Poland \\ ${ }^{3}$ Department of Surgery, University of Minnesota, Minneapolis, Minnesota, USA
}

Videosurgery Miniinv 2015; 10 (3): 359-362

DOI: $10.5114 /$ wiitm.2015.54085

\begin{abstract}
Introduction: Absent today is a simple numerical system of outcomes assessment that recognizes that bariatric surgery is metabolic surgery and incorporates weight loss, hypertension control, and type 2 diabetes control.

Aim: To introduce a simple, new Numerical Scale to Assess the Outcomes of Metabolic Surgery (NOMS).

Material and methods: For the stratification of weight outcomes, we used the percentage excess weight loss (\%EWL); for hypertension, the systolic blood pressure (SBP) and diastolic blood pressure (DBP) combined with medication usage; and for type 2 diabetes, the hemoglobin $A_{1 c}\left(H b A_{1}\right)$ value combined with medication usage.

Results: Utilizing the guidelines of the American Diabetes Association, the Working Group of the European Society of Hypertension, the European Society of Cardiology, and the American College of Cardiology/American Heart Association, we propose for \%EWL: W1 $\geq 50, W 2>25$ and $<50$, and W3 $\leq 25$; for hypertension H1 SBP/DPB $<140 / 90 \mathrm{~mm} \mathrm{Hg}$ on no medication, $H 2 S B P / D B P \geq 140 / 90 \mathrm{~mm} \mathrm{Hg}$ with improvement of SBP or possible reduction of antihypertensive medication, and $H 3$ no change or SBP higher than before surgery; for diabetes mellitus $D 1 H b A_{1 c} \leq 7 \%$ and no medication, $\mathrm{D} 2 \mathrm{HbA}_{1 \mathrm{c}}>7 \%$ with a decrease of the $\mathrm{Hb} \mathrm{A}_{1 \mathrm{c}}$ level or possible reduction of medication, $\mathrm{D} 3$ no change in $\mathrm{HbA} A_{1 c}$ or $\mathrm{Hb} A_{1 c}$ higher than before surgery. Designations of $\mathrm{HO}$ and $\mathrm{DO}$ are given if hypertension or diabetes was not present before surgery. Patient examples for numerical scores are provided.

Conclusions: The introduction of our numerical scale (NOMS) can be of benefit in metabolic/bariatric outcomes assessment; communications among metabolic/bariatric surgery centers, physicians, and patients; and for more precise reporting in the evidence-based literature.
\end{abstract}

Key words: numerical system, outcomes assessment, metabolic surgery, bariatric surgery, diabetes, comorbidities.

\section{Introduction}

The prevalence of obesity and related diseases caused by obesity or associated with it poses a huge challenge for modern medicine. The numbers of obese people in western civilizations continues to increase. There is no single state in the USA with less than $30 \%$ of the population affected by obesity [1]. Out of several therapeutic options developed in the $20^{\text {th }}$ century, only surgery offers long-lasting and effective treatment for obesity [2]. Surgical procedures continue to be in evolution. Not only have the surgical procedures changed, but patients' expectations of possible outcomes have changed as well.

One of the major changes in the perception of aims and outcomes of bariatric surgery has been the realization that bariatric surgery is metabolic

\section{Address for correspondence}

Maciej Bobowicz, Department of Oncological Surgery, Medical University of Gdansk, 17 Smoluchowskiego St, 80-214 Gdansk, Poland, phone: +48 608738 614, e-mail: bobowicz@gmail.com 
surgery. Today, emphasis is placed not only on the number of lost kilograms $(\mathrm{kg})$ or the reduction in the body mass index (BMI) as a result of surgery but also the impact of various surgical procedures on certain metabolic diseases [3]. Modern research also questions the classification of bariatric procedures based on the physiologic mechanisms of restriction, malabsorption or both. Metabolic surgery links all possible mechanisms of excess weight reduction such as regulation of the orexigenic and anti-orexigenic axes, the homeostasis of incretins and anti-incretins with foregut and hindgut theory, inflammatory background of obesity, and the impact of electrophysiological imbalances on weight gain and reduction [4-10]. Reporting of this extensive research on surgical outcomes requires simple and uniform means of communication between surgeons, other physicians, allied health specialists, and their patients.

Reviewing available literature, we noticed the absence of a simple and uniform classification of the results of surgical treatment of obesity. Bariatric surgeons use multiple tools to assess outcomes such as \% excess weight loss (\%EWL), the SF-36 questionnaire, the Sickness Impact Profile, the Quality of Well-Being Scale, and the Bariatric Analysis and Reporting Outcome System (BAROS), as well as some new concepts such as percent baseline weight loss $(\% \mathrm{WL})$ or $\mathrm{BMI}$ units lost $(\triangle \mathrm{BMI})$ [11-18]. All these tools lack balance between the assessment of weight loss and the assessment of the impact of bariatric surgery on other aspects of obesity. \%EWL is a simple measure that provides information on weight change only. On the other hand, the BAROS scale allows for a very broad assessment of multiple factors associated with obesity such as \%EWL, comorbidities, postoperative complications, reoperations, and finally the quality of life assessment in five domains: self-esteem, physical activity, social activity, work, and sexual activity [16]. The multitude of assessed factors makes the BAROS scale a very powerful instrument. It is, however, cumbersome to use on a daily basis in a busy bariatric center. Due to its complexity, its use in communications among medical practitioners is also difficult.

\section{Aim}

Based on the above considerations, we would like to introduce a simple, new Numerical Scale to
Assess the Outcomes of Metabolic Surgery (NOMS), not to replace BAROS but to supplement it.

\section{Material and methods}

We reviewed the American Diabetes Association Standards of Medical Care in Diabetes, 2014; the Guidelines of the Working Group of the European Society of Hypertension (ESH), 2013; the Guidelines of the European Society of Cardiology (ESC), 2013; and the Guidelines of the American College of Cardiology/American Heart Association (AHA), 2013 [19-23]. These guidelines were combined with a stratification of bariatric weight outcome, expressed as the \%EWL as follows: \%EWL > 50 - very good, \%EWL 50-25 - average/satisfactory, \%EWL $<25$ - unsatisfactory/failure.

A numerical scale assessing the outcomes of metabolic/bariatric surgery should be simple, easy to obtain, and, therefore, based on a minimal number of gradable outcomes, comparable to the TNM classification of tumors developed by the Union for International Cancer Control [24]. For our numerical classification, we chose to use three cardinal outcomes of metabolic/bariatric surgery, each having a precise numerical metric for evaluation:

- weight change: symbol W; determined by \%EWL;

- arterial hypertension control: symbol $\mathrm{H}$; determined by arterial blood pressure (BP);

- diabetes mellitus control: symbol D; determined by hemoglobin $\mathrm{A}_{1 \mathrm{c}}$ levels $\left(\mathrm{HbA}_{1 \mathrm{c}}\right)$.

An extension of this numerical scale to other outcomes, e.g., obstructive sleep apnea control, can be added to this basic nomenclature as desired.

\section{Results}

The bases for the numerical scale for the assessment of metabolic/bariatric surgery with the three parameters of weight change, arterial hypertension control, and type 2 diabetes mellitus control are presented in Table I.

Examples:

- Patient A: \%EWL > 50\%, hypertension slightly improved (BP 160/90 mm Hg), $\mathrm{HbA}_{1 \mathrm{c}}>7 \%$, still requires antidiabetic and antihypertensive medication - W1H2D3.

- Patient B: \%EWL < 25\%, blood pressure returned to normal ( $\mathrm{BP}<140 / 90 \mathrm{~mm} \mathrm{Hg}$ ), $\mathrm{HbA}_{1 c}<6 \%$, does not require any diabetic or hypertensive medication - W3H1D1. 
Table I. A numerical scale to assess the outcomes of metabolic/bariatric surgery (NOMS)

\begin{tabular}{|c|c|c|}
\hline Parameter & Outcome value & Additional comments \\
\hline \multicolumn{3}{|c|}{ Weight change } \\
\hline W1 & $\% E W L \geq 50$ & \\
\hline W2 & $50>\% \mathrm{EWL}>25$ & \\
\hline W3 & $\% \mathrm{EWL} \leq 25$ & \\
\hline \multicolumn{3}{|c|}{ Hypertension } \\
\hline $\mathrm{HO}$ & No hypertension before surgery & \\
\hline $\mathrm{H} 1$ & $\mathrm{SBP} / \mathrm{DBP}<140 / 90 \mathrm{~mm} \mathrm{Hg}$ & No medication \\
\hline $\mathrm{H} 2$ & $\mathrm{SBP} / \mathrm{DBP} \geq 140 / 90 \mathrm{~mm} \mathrm{Hg}$ & $\begin{array}{l}\text { Improvement of SBP or possible reduction } \\
\text { of antihypertensive medication }\end{array}$ \\
\hline H3 & No change or SBP higher than before surgery & \\
\hline \multicolumn{3}{|c|}{ Diabetes mellitus } \\
\hline DO & No DMT2 before surgery & \\
\hline D1 & $\mathrm{HbA}_{1 \mathrm{c}} \leq 7 \%$ & No medication \\
\hline D2 & $\mathrm{HbA}_{1 \mathrm{c}}>7 \%$ & $\begin{array}{c}\text { Decrease of the } \mathrm{HbA}_{1 c} \text { level or possible reduction } \\
\text { of medication }\end{array}$ \\
\hline D3 & $\begin{array}{c}\text { No change in } \mathrm{HbA}_{1 c} \\
\text { or } \mathrm{HbA}_{1 c} \text { higher than before surgery }\end{array}$ & \\
\hline
\end{tabular}

- Patient C: \%EWL $=40 \%$, no previous diabetes or hypertension, normal BP and $\mathrm{HbA}_{1 \mathrm{c}}$ values W2HODO.

\section{Discussion}

The main objective of bariatric surgery is certainly weight reduction, most universally expressed by \%EWL. With the emphasis on metabolic/bariatric surgery, or even pure metabolic surgery without significant weight loss, the main objectives of therapy become control or resolution of hypertension and type 2 diabetes [2, 25, 26]. The American Diabetes Association (ADA) Standards of Medical Care in diabetes, 2014, set three major goals that would lead to significant improvement of diabetes, arterial hypertension, and obesity [19]. These goals are for $\mathrm{HbA}_{1 \mathrm{c}}$ to be less than 7\%; systolic BP < $140 \mathrm{~mm} \mathrm{Hg}$, diastolic $\mathrm{BP}<80 \mathrm{mg} \mathrm{Hg}$; and LDL-cholesterol < $100 \mathrm{mg} / \mathrm{dl}$. The Guidelines of the Working Group of the European Society of Hypertension (ESH) and the European Society of Cardiology (ESC), 2013, define high normal values of blood pressure at systolic BP $\leq 139 \mathrm{~mm} \mathrm{Hg}$ and diastolic BP $\leq 89 \mathrm{~mm} \mathrm{Hg}[20,21]$. The American Heart Association, in its latest recommendations from 2013, sets several different BP goal levels de- pending on ethnicity, age, and comorbidities [22, 23]. To establish the guidelines for our numerical classification, we decided to incorporate the BP recommendations for adults younger than 60 years of age, as they reflect the majority of patients submitted to metabolic/bariatric surgery today and are consistent with the recommendations of the ESH and ESC.

The proposed numerical scoring system can be easily determined and incorporated in each patient's records from the time of the first postoperative visit. Comparisons to subsequent visits, and long-term follow-up, allows for the monitoring of satisfactory or non-satisfactory changes in the three primary outcomes of metabolic/bariatric surgery over time. The proposed numerical determination should be of benefit to the staff and to the patients of any given metabolic/bariatric surgery center or practice, as well as to enhanced communications among different metabolic/bariatric surgery centers and physicians representing various specialties. Furthermore, use of the proposed numerical scale can facilitate studies comparing different metabolic/bariatric procedures, centers, and regions. By its adaptation, this scale can allow for more precise reporting in the evidence-based literature. 


\section{Conclusions}

The introduction of our numerical scale meets two needs of metabolic/bariatric surgery: a simple manner in which to express postoperative outcomes and a tool that acknowledges and assesses the immutable marriage of bariatric and metabolic surgery.

\section{Conflict of interest}

Doctors Maciej Michalik, Maciej Bobowicz, and Henry Buchwald declare that they have no conflict of interest or financial ties to disclose.

\section{Ethical approval}

This article does not contain any studies with human participants or animals performed by any of the authors.

\section{References}

1. World Health Organization. WHO Global Infobase.https://apps. who.int/infobase/Comparisons.aspx accessed on 10 Sep 2014.

2. Executive summary: Guidelines (2013) for the management of overweight and obesity in adults: a report of the American College of Cardiology/American Heart Association Task Force on Practice Guidelines and the Obesity Society published by the Obesity Society and American College of Cardiology/American Heart Association Task Force on Practice Guidelines. Based on a systematic review from the Obesity Expert Panel, 2013. Obesity (Silver Spring) 2014; 22 (Suppl. 2): S5-39.

3. Buchwald H, Avidor $Y$, Braunwald E, et al. Bariatric surgery: a systematic review and meta-analysis. JAMA 2004; 292: 1724-37.

4. Cummings DE, Overduin J, Foster-Schubert KE. Gastric bypass for obesity: mechanisms of weight loss and diabetes resolution. J Clin Endocrinol Metab 2004; 89: 2608-15.

5. Whitson BA, Leslie DB, Kellogg TA, et al. Entero-endocrine changes after gastric bypass in diabetic and nondiabetic patients: a preliminary study. J Surg Res 2007; 141: 31-9.

6. Rubino F, Marescaux J. Effect of duodenal-jejunal exclusion in a non-obese animal model of type 2 diabetes: a new perspective for an old disease. Ann Surg 2004; 239: 1-11.

7. Pradhan AD, Manson JE, Rifai N, et al. C-reactive protein, interleukin 6 , and risk of developing type 2 diabetes mellitus. JAMA 2001; 286: 327-34.

8. Gregor MF, Hotamisligil GS. Inflammatory mechanisms in obesity. Annu Rev Immunol 2011; 29: 415-45.

9. Xu H, Barnes GT, Yang Q, et al. Chronic inflammation in fat plays a crucial role in the development of obesity-related insulin resistance. J Clin Invest 2003; 112: 1821-30.

10. Sanmiguel CP, Conklin JL, Cunneen SA, et al. Gastric electrical stimulation with the TANTALUS System in obese type 2 diabetes patients: effect on weight and glycemic control. J Diabetes Sci Technol 2009; 3: 964-70.
11. Ware JE, Sherbourne CD. The MOS 36-item short-form health survey (SF-36) I: conceptual framework and item selection. Med Care 1992; 30: 473-83.

12. De Bruin A, Diederiks J, De Witte L, et al. The development of a short generic version of the sickness impact profile. J Clin Epidemiol 1994; 47: 407-18.

13. Kaplan RM, Sieber, WJ, Ganiats TG. Comparison of the quality of well-being scale with a self-administered questionnaire. Psychol Health 1997; 12: 783-91.

14. Kaplan RM, Bush JW. Health-related quality of life measurement for evaluation research and policy analysis. Health Psychol 1982; 1: 61-80.

15. Oria HE, Moorehead MK. Bariatric analysis and reporting outcome system (BAROS). Obes Surg 1998; 8: 487-99.

16. Oria HE, Moorehead MK. Updated bariatric analysis and reporting outcome system (BAROS). Surg Obes Relat Dis 2009; 5: 60-6.

17. Hatoum IJ, Kaplan LM. Advantages of percent weight loss as a method of reporting weight loss after Roux-en-Y gastric bypass. Obesity 2013; 21: 1519-25.

18. van de Laar AW. Algorithm for weight loss after gastric bypass surgery considering body mass index, gender, and age from the Bariatric Outcome Longitudinal Database (BOLD). Surg Obes Relat Dis 2014; 10: 55-61.

19. American Diabetes Association. Executive summary: standards of medical care in diabetes: 2014. Diabetes Care 2014; 37 (Suppl. 1): S5-13.

20. Mancia G, Fagard R, Narkiewicz K, et al. 2013 ESH/ESC Practice Guidelines for the management of arterial hypertension. Blood Press 2014; 23: 3-16.

21. Wenger NK. Prevention of cardiovascular disease: highlights for the clinician of the 2013 American College of Cardiology/ American Heart Association guidelines. Clin Cardiol 2014; 37: 239-51.

22. Anthony D, George P, Eaton CB; 2013 American College of Cardiology/American Heart Association; Eighth Joint National Committee. Cardiac risk factors: new cholesterol and blood pressure management guidelines. FP Essent 2014; 421: 28-43.

23. Kavousi M, Leening MJ, Nanchen D, Comparison of application of the ACC/AHA guidelines, Adult Treatment Panel III guidelines, and European Society of Cardiology guidelines for cardiovascular disease prevention in a European cohort. JAMA 2014; 311: 1416-23.

24. http://www.uicc.org/resources/tnm

25. Vest AR, Heneghan HM, Agarwal S, et al. Bariatric surgery and cardiovascular outcomes: a systematic review. Heart 2012; 98: 1763-77.

26. Athyros VG, Tziomalos K, Karagiannis A, Mikhailidis DP. Cardiovascular benefits of bariatric surgery in morbidly obese patients. Obes Rev 2011; 12: 515-24.

Received: 30.07.2015, accepted: 19.08.2015. 